\title{
Effect of orientation of lunar apse on earthquakes
}

\author{
B. L. Gupta \\ CH3/56 Kendriya Vihar, Kharghar, Sector-11, Navi Mumbai-410 210, India. E-mail: bl.gupta@mtnl.net.in. \\ Tel: 91-22-27744344. Fax: 91-22-27744344. \\ Accepted 18 April, 2011
}

\begin{abstract}
There were 6563 earthquakes of magnitude $1.0-2.9$ in 1993 and 10233 in 2003. The lunar apse was at about $90^{\circ}$ to the axis of rotation of the earth. The number of earthquakes of magnitude 3.0 to 4.9 between 2000 and 2005 increased when the minimum perigee moved from North Pole to South Pole. The decrease in earthquakes of magnitude 1.0- 2.9 after 2003 in Mediterranean region was accompanied by an increase of earthquakes of magnitude 3.0 - 4.9 in Pacific sea region. The minimum perigee nearer to South Pole of Earth decreased the number of earthquakes of magnitude 5.0 to 5.9 from 1542 in 1994 to 979 in 1998. The minimum perigee nearer to North Pole of Earth increased the number of earthquakes of magnitude 5.0 to 5.9 from 979 in 1998 to 1203 in 2003. The apse parallel to the axis of rotation of earth in 1990, 1995, 1999, 2004 and 2008 increased the number of large earthquakes in these years. From 2004 - 08 (April-September), 33 out of 34 large earthquakes were close to $28,0,-28$ and $-0^{\circ}$ lunar declinations. During the same year (October - March), 29 out of 39 large earthquakes were close to above lunar declinations.
\end{abstract}

Key words: Plate tectonics, mantle convection, Sun-Earth-Moon interaction, perigee-apogee, lunar phases, lunar declination, earthquake triggering.

\section{INTRODUCTION}

The Earth's crust is about $30 \mathrm{~km}$ thick, followed by mantle up to a depth of about $2890 \mathrm{~km}$, core up to depth of about $5150 \mathrm{~km}$ and inner core further up to a depth of about $6378 \mathrm{~km}$. The mantle can be divided into an upper portion, the asthenosphere from about 100 to $350 \mathrm{~km}$ deep which is approximately $10 \%$ molten, and a lower portion, which is $100 \%$ solid. The uppermost mantle, from about $100 \mathrm{~km}$ deep to the base of the crust, is $100 \%$ solid, as is the crust. Because the earth is very hot inside, a current of heat flows from the core to the crust (Mantle plumes). This is called convection current (Bridge, 1999; Carrez et al., 2007; Helffrich and Wood, 2001; Hernlund and Tackley, 2007; Loper, 1998; Maruyama et al., 2007; Putirka et al., 2007; Samuel and Bercovici, 2006; Schellart et al., 2006; Sima and Agterberg, 2006; Simmons et al., 2006; Stevenson, 2003; Walzer and Hendel, 1999; Zhao, 2004). This current cools down as it comes closer to the surface of the earth. As a result, the rising of the current decreases and goes into horizontal direction along the bottom of the crust. When the current cools down more, the convection current descends again and goes to the inner Earth. There the temperature increases and the current rises again. This goes on and on. When the current comes at a weaker part of the crust, for example at a volcano, magma comes above the earth's surface. There are three distinct changes in velocity structure, at depths of 410,660 and $2,700 \mathrm{~km}$. The slabs of subducted lithosphere can sink deep into Earth's lower mantle. The plate mode of convection is responsible for $90 \%$ of the heat loss from the mantle, while the plume mode covers the remaining $10 \%$. The convection current along the bottom of the crust causes the moving of the tectonic plates. This is called plate tectonics (Ricou, 2004; Sima and Agterberg, 2006). The movement of these plates goes very slowly. The bumping of two tectonic plates causes an earthquake.

The mass of the moon is $7.35 \times 10^{22} \mathrm{~kg}$ and its diameter is $3476 \mathrm{~km}$. The moon's mass is 81 times less than the earth's. The moon's diameter is a quarter that of the earth. The centre of mass of the earth-moon system is at a distance of about $4800 \mathrm{~km}$ from the centre of earth in the direction of moon or about $1578 \mathrm{~km}$ from the surface of the earth. This centre is almost in the middle of mantle. The orbit of the moon has a $5^{\circ}$ inclination to the ecliptic plane which results from perturbations caused by the sun. The moon's inclination to the Earth's equator therefore varies between 18 and $28^{\circ}$. The largest separation between the earth and moon on its orbit is called 
apogee and the smallest separation is called perigee (Walker, 1997). At perigee, the distance is about 365,000 $\mathrm{km}$; at apogee, the distance is about $409,000 \mathrm{~km}$. The average distance is about $385,000 \mathrm{~km}$, or about 60 times the radius of the earth itself. The difference between minimum perigee and maximum apogee is about 50000 $\mathrm{km}$. Therefore, the distance of the centre of earth from the common centre of gravity varies by about $610 \mathrm{~km}$ during the lunar month since the moon's mass is 81 times less than the earth's. The lunar apse, rotating counter clockwise in the plane of the moon's orbit and moves $360^{\circ}$ in 8.849 years (the lunar-apse cycle). The position of apse changes only by about $41^{\circ}$ in a year. By contrast, the lunar node (line of intersection of plane of moon's orbit with plane of earth's orbit) rotates counterclockwise in the plane of the earth's orbit and moves $360^{\circ}$ in 18.6 (the lunar nodal cycle). Approximately every 3 years, the apse and the node coincide. The ascending node is where the moon crosses the plane of the ecliptic from south to north and the descending node is where the moon crosses the plane of the ecliptic from north to south.

There are four types of seismic zones (USGS, NEIC). The first follows the line of mid-ocean ridges. Associated with this type of seismicity is the volcanic activity along the axis of the ridges. The second type of earthquake is the shallow-focus event unaccompanied by volcanic activity. In these faults, two mature plates are scraping by one another. The friction between the plates can be so great that very large strains can build up before they are periodically relieved by large earthquakes. The third type of earthquake is related to the collision of oceanic and continental plates. One plate is thrust or subducted under the other plate so that a deep ocean trench is produced. This type of earthquake can be shallow, intermediate, or deep, according to its location on the down going lithospheric slab. The fourth type of seismic zone occurs along the boundaries of continental plates. Typical of this is the broad swath of seismicity from Burma to the Mediterranean, crossing the Himalayas, Iran, and from Turkey to Gibraltar. Most scientists now favor the notion that forces associated with subduction are more important than seafloor spreading. About $90 \%$ of all earthquakes are produced at plate boundaries where two plates are colliding, spreading apart, or sliding past each other. It seems that low magnitude earthquakes are more frequent at the boundaries of Eurasian and African plates in the Mediterranean Sea region and they are more for certain position of the moon and the sun.

Earlier, some efforts were made to correlate the earthquakes with moon's gravity (Cotton, 1922; Emter, 1997; Heaton, 1982; Leypoldt, 1941; Melchior, 1983; Rydelek et al., 1992; Stetson, 1935) and astronomical or geophysical phenomena (Allen, 1936; Jeffreys, 1938; Knott, 1886; Lamkin, 1966; Landsberg, 1940; Perrine, 1949; Sun, 1992; Varga and Grafarend, 1996). The most frequently considered perturbations have been solid earth and ocean tides. Landsberg (1940) proposed periodicities in earthquake occurrence as a consequence of the wandering of the Earth's axis of rotation. Van den Dungen et al. (1951) considered the correlation between irregularities in the speed of earth rotation and seismicity. It was shown that tidal perturbations are a triggering mechanism (Trifunac, 1970). Heaton (1982) did not find any correlation for either tidal shear stress or tidal normal-to-the-fault compressive stresses with shallow strike-slip earthquakes or with deep earthquakes. Tsuruoka et al. (1995) concluded that a decrease in the confining pressure due to earth tide is responsible for triggering earthquake occurrence. Such clear phase selectivity was not seen for strike-slipand thrust-type earthquakes. However, recently it was concluded that there is no correlation of earthquakes with earth tides (Vidale et al., 1998).

The drift of the plates across the surface of the earth has been going on over millions of years. Historical earthquake theories have been analysed by Oeser (1996). No significant effect of moon on triggering of earthquake has been accepted. When the historical earthquake theories were discussed, the existence of mantle below the crust was not known and it was thought that forces from the core may not affect the crust. The present paper examines the correlations of the occurrence of earthquakes of different magnitudes with various lunar positions in its orbit around the earth.

\section{RESULTS AND DISCUSSION}

The extensive earthquake data is available at USGS (2011), NEIC (2011) and EMSC (2011). The statistical data in Figures 1 - 5 from USGS, NEIC shows earthquakes of different magnitudes from 1990 to 2008. The earthquakes of magnitude 1.0 to 2.9 in Figure 1 show considerable variation. There are two peaks in 1993 and 2003, and a minimum in 1996. The earthquakes of magnitude 3.0 to 4.9 in Figure 2 increase before 1995 and are almost stable at about 13000/year from 1995 to 2000, showing an increase later and again stabilizing at about 23000/year in 2005. The earthquakes of magnitude 5.0 to 5.9 in Figure 3 show large variation with a minimum in 1998 (979/year) and a peak in 2007 (2074/year). In this figure, the earthquakes are reduced after 1994 (1542/year) and increase after 1998. There is a large increase after 2003 from 1203/ year in 2003 to 2074/year in 2007 and the number stabilized afterwards. In Figure 4, the large earthquakes show peaks in the year 1990, 1995, 1999, 2004 and 2008. The total number of earthquakes of all magnitudes in Figure 5 is almost stable at about 20000/year from 1993 to 1999, showing an increase later and again stabilizing at about 31000/year. For the years 1998 to 2003, the number of total earthquakes increased by $9731 /$ year. For the same period the earthquakes of magnitude 1.0 to 4.9 increased by $8175 /$ year. Thus, the increase in the number of total earthquakes is mostly due to the increase in the number of earthquakes of magnitude 1.0 to 4.9. From these figures, it is quite apparent that the trends for earthquakes 


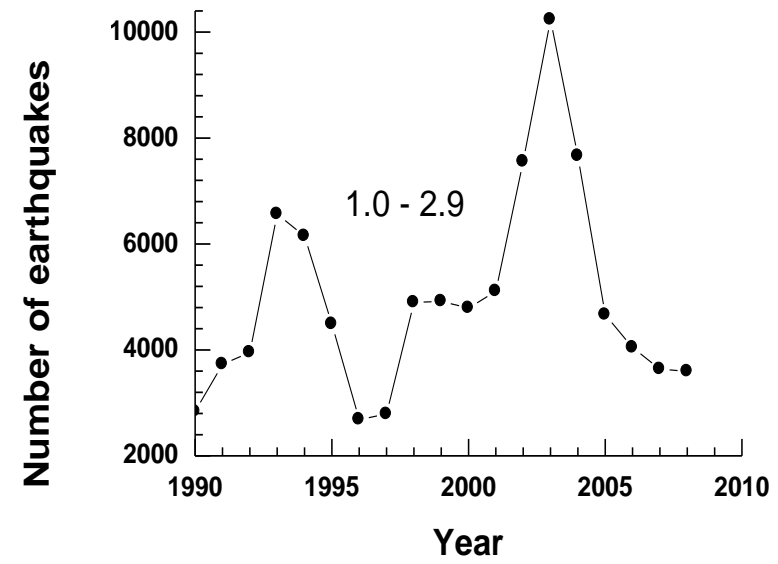

Figure 1. Plot of number of earthquakes of magnitude 1.02.9 each year.

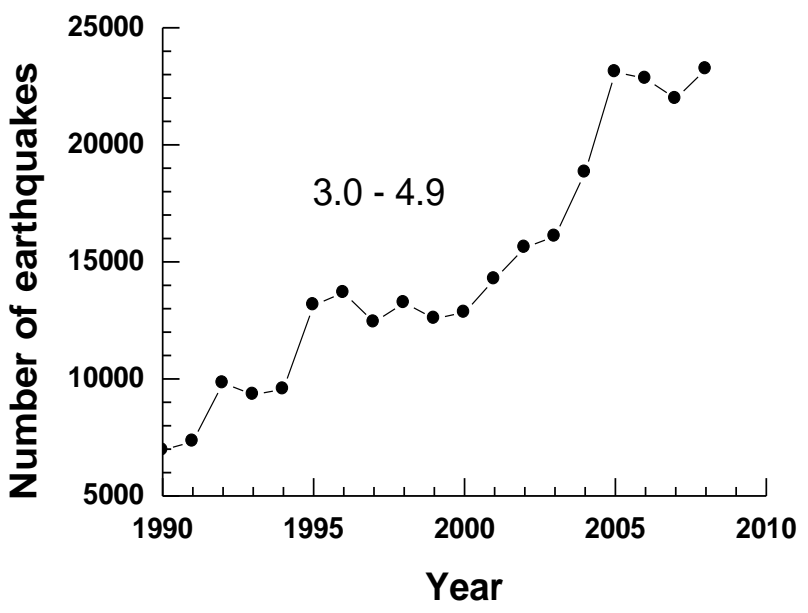

Figure 2. Plot of number of earthquakes of magnitude 3.04.9 each year.

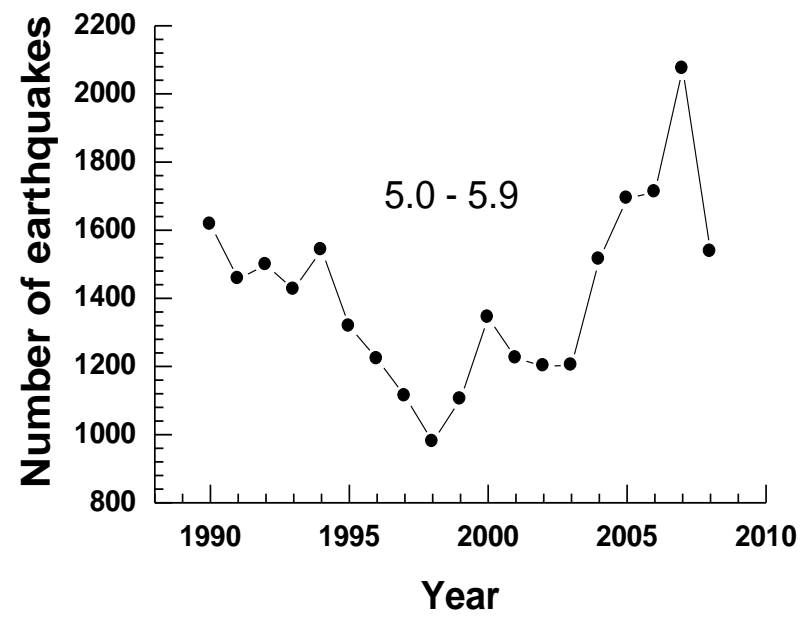

Figure 3. Plot of number of earthquakes of magnitude 5.05.9 each year.

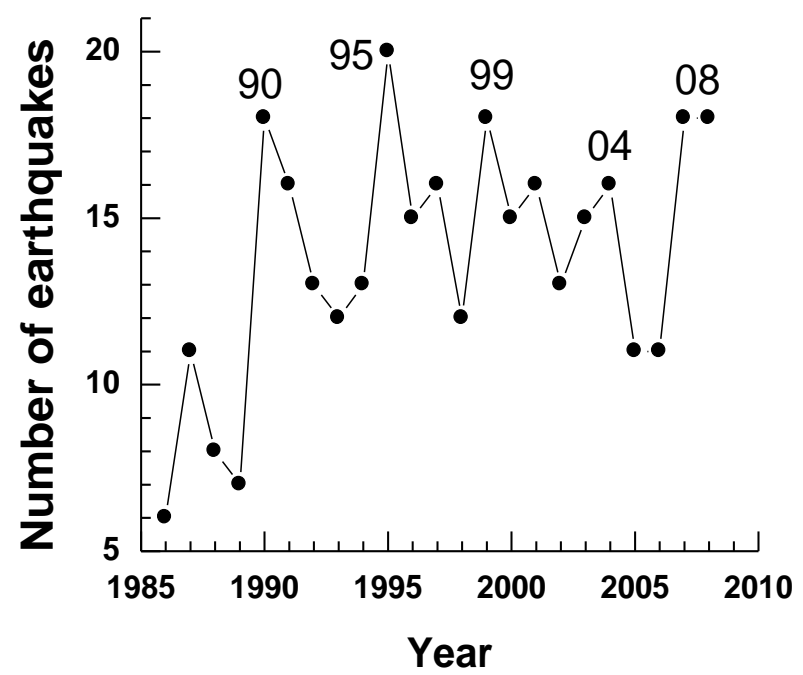

Figure 4. Plot of number of large earthquakes each year.

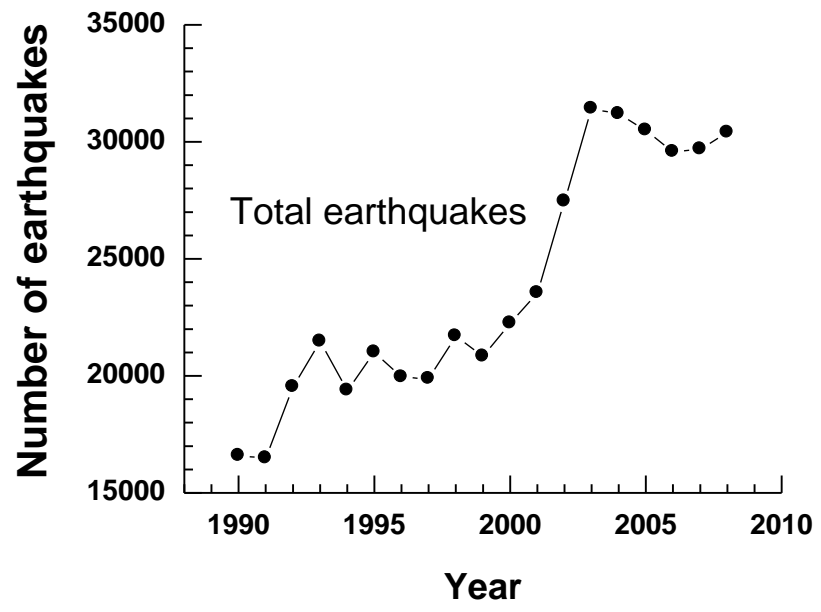

Figure 5. Plot of number of total earthquakes each year.

of different magnitudes are not the same.

The lunar perigee is minimal when the moon is nearest to full moon/new moon position. It is maximal when the moon is at about $90^{\circ}$ to the full moon/new moon position. In any year, the direction of lunar apse is near minimum perigee. Table 1 shows positions of minimum perigees in different years from 1992 - 2009 (Walker, 1997; Geoscience, 2007). In 2008, the minimum perigee near full moon was on 12 December, while near new moon was on 3rd June. In this year, the lunar apse was almost parallel to the axis of rotation of the earth. In the same year, the maximum perigee at about $90^{\circ}$ to the full moon/ new moon positions was on 14th February and 20th September. In 1999, the lunar positions were similar. The minimum perigee near full moon was on22nd December, while near new moon was on 15th May. In this year, the 
Table 1. Positions of minimum perigees in different years from 1993-2009 near Full Moon.

\begin{tabular}{lcc}
\hline Day of perigee & Perigee (km) & Perigee position \\
\hline 19 Jan 1992 & 356548 & $\mathrm{~F}+0 \mathrm{~h}$ \\
8 Mar 1993 & 356529 & $\mathrm{~F}-1 \mathrm{~h}$ \\
25 Apr 1994 & 356925 & $\mathrm{~F}-2 \mathrm{~h}$ \\
13 June 1995 & 357006 & $\mathrm{~F}-2 \mathrm{~h}$ \\
30 July 1996 & 356948 & $\mathrm{~F}-2 \mathrm{~h}$ \\
16 Sep 1997 & 356965 & $\mathrm{~F}-3 \mathrm{~h}$ \\
4 Nov 1998 & 356614 & $\mathrm{~F}-4 \mathrm{~h}$ \\
22 Dec 1999 & 356654 & $\mathrm{~F}-6 \mathrm{~h}$ \\
19 Jan 2000 & 359362 & $\mathrm{~F}-1 \mathrm{~d}$ \\
7 Feb 2001 & 356852 & $\mathrm{~F}-8 \mathrm{~h}$ \\
27 Feb 2002 & 356897 & $\mathrm{~F}+10 \mathrm{~h}$ \\
17 Apr 2003 & 357157 & $\mathrm{~F}+9 \mathrm{~h}$ \\
3 June 2004 & 357248 & $\mathrm{~F}+8 \mathrm{~h}$ \\
21 July 2005 & 357159 & $\mathrm{~F}+8 \mathrm{~h}$ \\
8 Sep 2006 & 357174 & $\mathrm{~F}+8 \mathrm{~h}$ \\
26 Oct 2007 & 356754 & $\mathrm{~F}+6 \mathrm{~h}$ \\
12 Dec 2008 & 356567 & $\mathrm{~F}+4 \mathrm{~h}$ \\
10 Jan 2009 & 357500 & $\mathrm{~F}-16 \mathrm{~h}$ \\
\hline
\end{tabular}

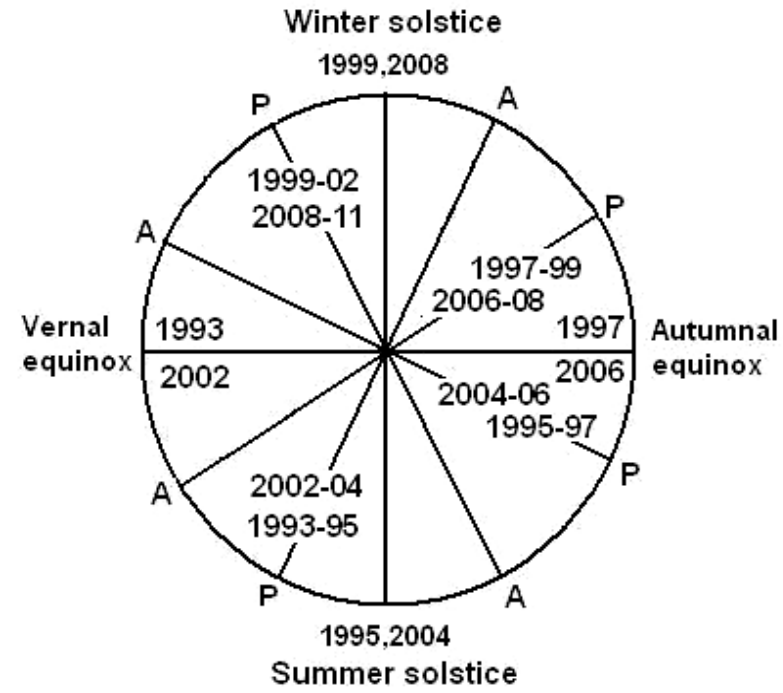

Figure 6. Lunar apse positions during the years 1993 to 2008 .

lunar apse was not exactly parallel to the axis of rotation of the earth. In 1995, the minimum perigee near full moon was on 13th June, while near new moon was on 22nd December. In 2004, the lunar positions were similar. The minimum perigee near full moon was on 3rd June, while near new moon was on 12th December. In that year, the lunar apse was almost parallel to the axis of rotation of the earth. In 1993, 1997, 2002 and 2006, the apse was almost at $90^{\circ}$ to the axis of rotation of the earth. These

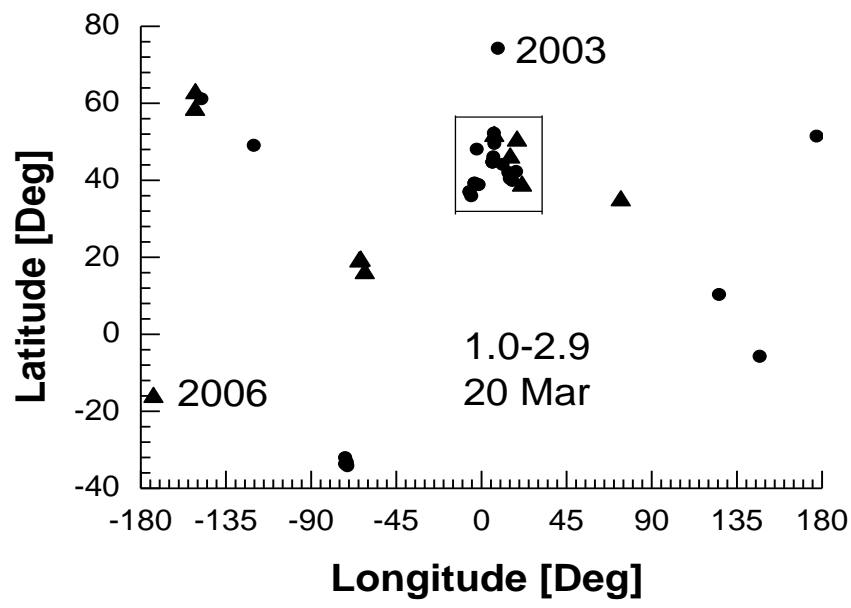

Figure 7. Earthquakes of magnitude 1.0-2.9 on 20th March 2003 and 2006.

positions of lunar apse are summarized in Figure 6.

The two peaks in 1993 and 2003 in Figure 1 suggest that, orientation of lunar apse at about $90^{\circ}$ to the axis of rotation of the earth (Figure 6) increases the number of earthquakes of magnitude $1.0-2.9$. Similar orientation of lunar apse in 1997 and 2006 (Figure 6) reduces the number of these earthquakes. In 1993 and 2003, the minimum perigees were near full moon of March and April, respectively. In 1997 and 2006, the minimum perigees were near full moon of September. There was a change in orientation of apse by $180^{\circ}$.

The earthquakes of magnitude 3.0 to 4.9 in Figure 2 are almost stable at about 13000/year from 1995 to 2000 . In 1995, the minimum perigee was near full moon of June, that is, the perigee was towards south pole of the earth and it moved by about $180^{\circ}$ in 1999 , near full moon of December, that is, the perigee moved towards north pole of the earth. During these years, the minimum perigee remained in the ascending node. The perigee shifted to descending node in 2000 and remained in this node till 2004. During this period, there was a considerable increase in the number of earthquakes in Figure 2. In 2005, the number of earthquakes again stabilized since the minimum perigee moved to ascending node. The decrease in earthquakes of magnitude 1.0 - 2.9 after 2003 till about 2006 in Figure 1 was accompanied by the rapid increase of earthquakes of magnitude 3.0 - 4.9 after 2003 in Figure 2. The earthquakes of magnitude 1.0 - 2.9 on 20th March (vernal equinox) reduced from 30 in 2003 to 11 in 2006 . There was a similar reduction of these earthquakes on 20th September (autumnal equinox) from 58 in 2003 to 15 in 2006. On the other hand, the earthquakes of magnitude 3.0 - 4.9 on 20 March increased from 41 in 2003 to 79 in 2006. There was no significant increase of these earthquakes on 20th September from 36 in 2003 to 37 in 2006. Figures 7-11 show the positions of these earthquakes 


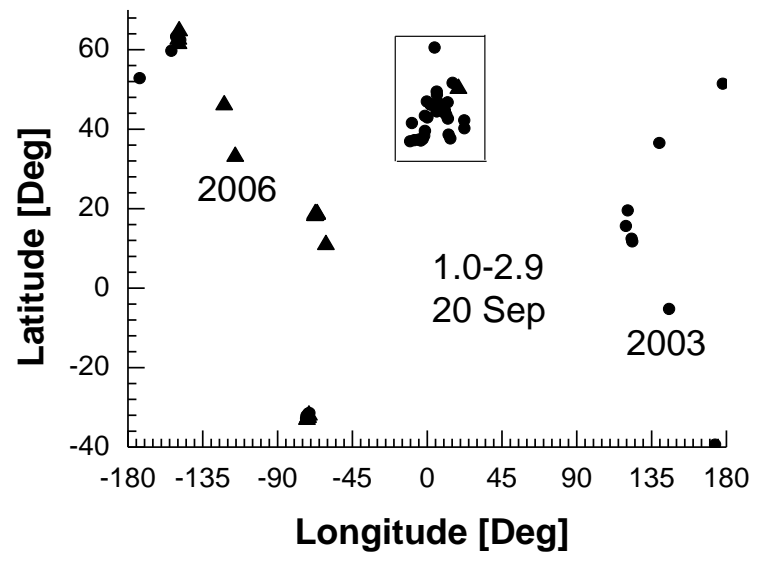

Figure 8. Earthquakes of magnitude $1.0-2.9$ on 20th September, 2003 and 2006.

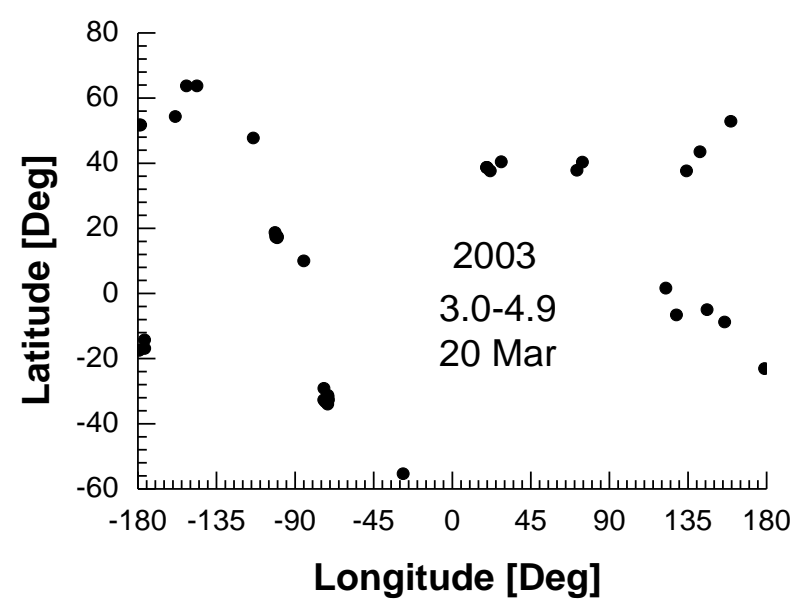

Figure 9. Earthquakes of magnitude $3.0-4.9$ on 20th March, 2003.

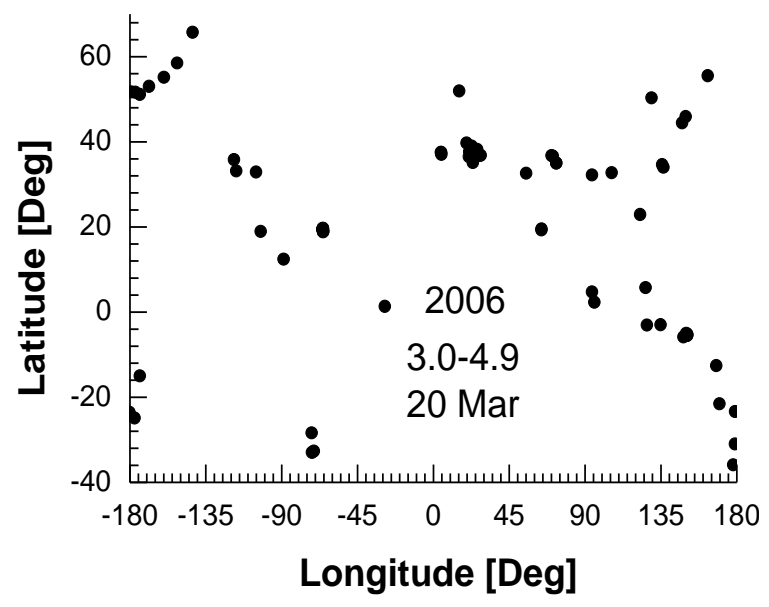

Figure 10. Earthquakes of magnitude $3.0-4.9$ on 20th March, 2006.

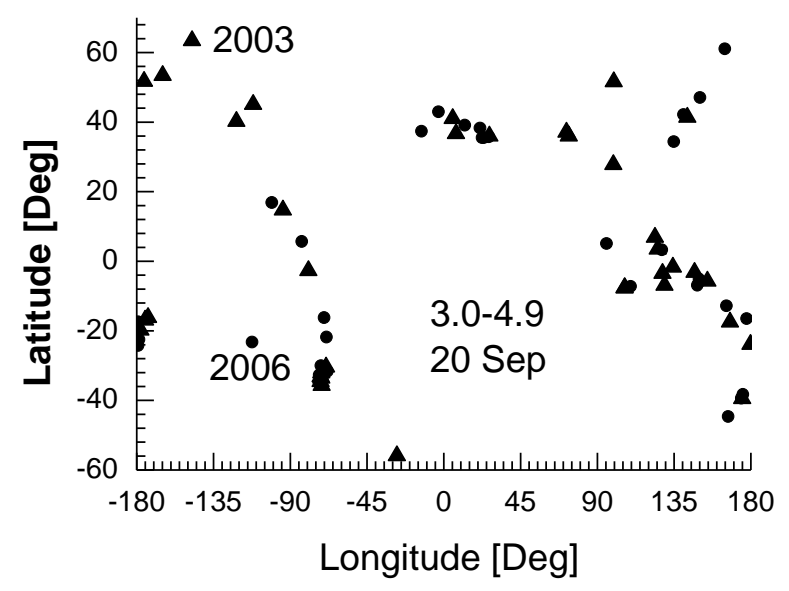

Figure 11. Earthquakes of magnitude $3.0-4.9$ on 20th September, 2006.

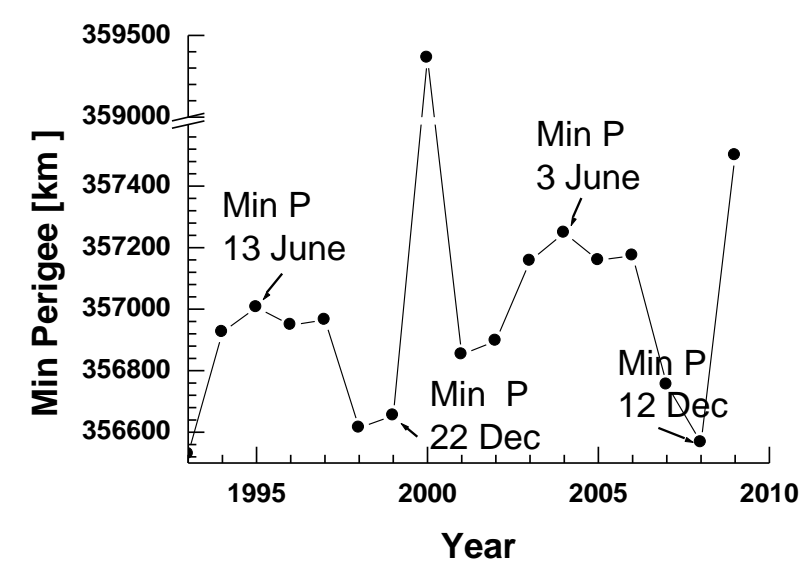

Figure 12. Plot of minimum perigee for the years $1993-2009$.

on 20th March 2003 and 20 September 2006. The earthquakes of magnitude 1.0 - 2.9 in Mediterranean region in 2003 were considerably reduced in 2006 (Figures 7 and 8). The earthquakes of magnitude 3.0 4.9 seem to be more around the Pacific sea region (Figures 9 - 11).

Figure 12 gives a plot of minimum perigee for various years from Table 1. After 1994 in Figure 12, the minimum perigee stabilized but the number of earthquakes of magnitude between 5.0 - 5.9 decreased in Figure 3. After 1997, the minimum perigee reduced, and the decrease in the number of earthquakes continued up to 1998 in Figure 3 . The minimum perigee closer to full moon and nearer to South Pole of the earth (Figure 6) seems to decrease the number of earthquakes of magnitude 5.0 to 5.9 in Figure 3. From 1998 to 2002/2003 in Figure 12, the minimum perigee increased and there was a slow increase in the number of earthquakes till 2003 in Figure 3 . The minimum perigee closer to full moon and nearer to north pole of the earth (Figure 6) seems to increase the 


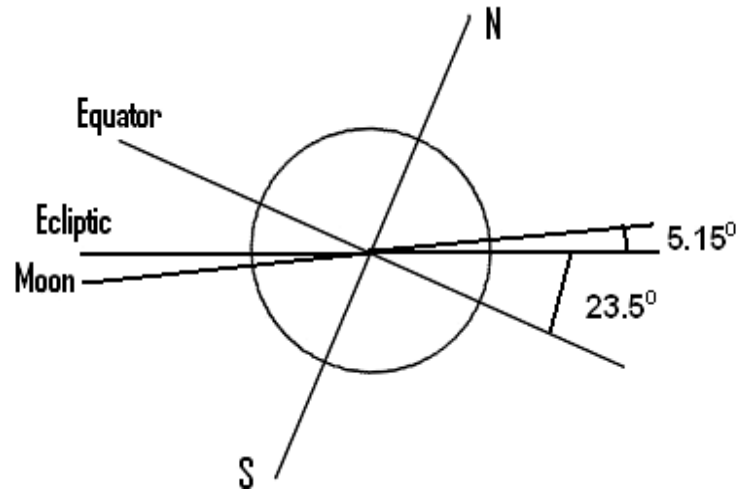

Figure 13. Inclination of lunar orbit from ecliptic.

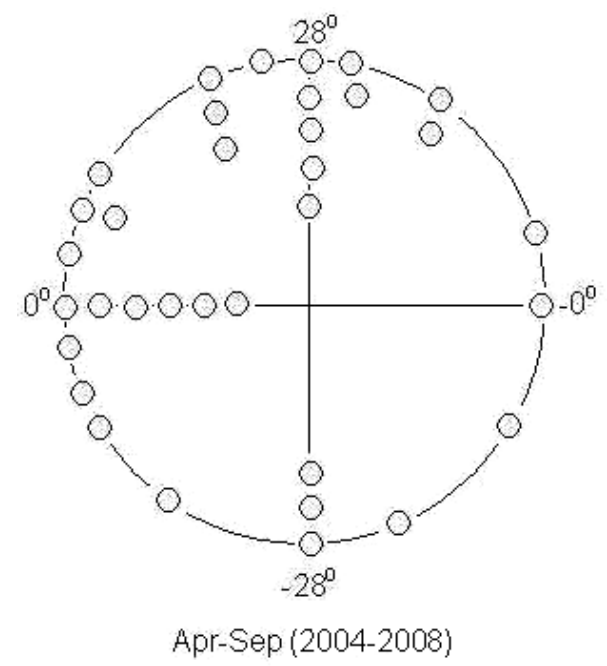

Figure 14. Positions of large earthquakes with respect to lunar declination in the months of April to September during 2004 to 2008.

number of earthquakes of magnitude 5.0 to 5.9 in Figure 3. The stability of minimum perigee after 1994 in Figure 12 , showed a reduction in the number of earthquakes in Figure 3 while the stability of minimum perigee after 2003 in Figure 12 shows a rapid increase in the number of earthquakes in Figure 3. The main difference between these two situations seems to be that while after 1993, the minimum perigee was before the full moon and after 2003, the minimum perigee was after the full moon (Table 1). In 1994, the minimum perigee was on 25th April while in 2003, the minimum perigee was on 17th April. This deviation slightly increased the separation between the lunar apse and axis of rotation of the earth. This shows that the orientation of the lunar apse significantly affects the number and magnitude of earthquakes.

The various peaks for large earthquakes in Figure 4 seem to follow lunar apse cycle. The apse is almost parallel to the axis of rotation of the earth in 1990, 1995,

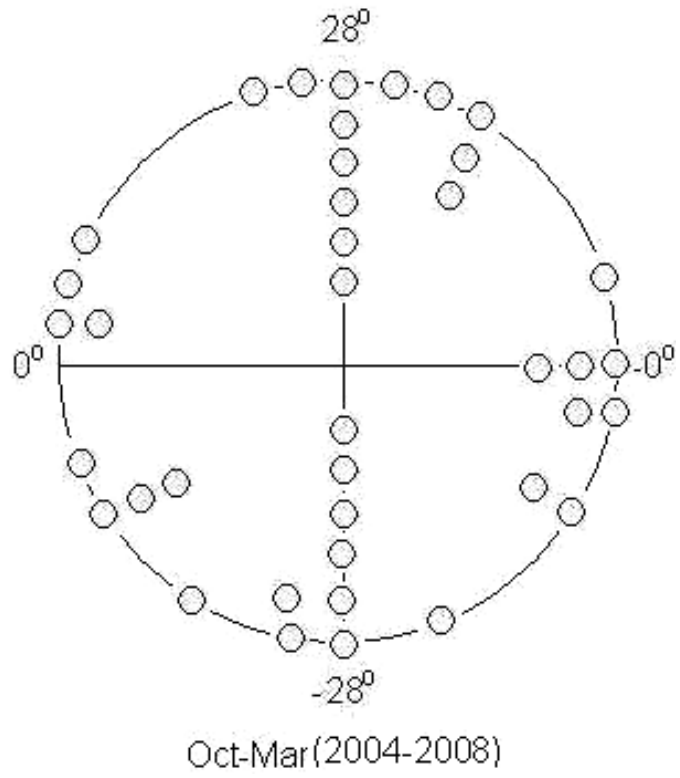

Figure 15. Positions of large earthquakes with respect to lunar declination in the months of October to March during 2004 to 2008.

1999, 2004 and 2008 (Figure 6) which seems to increase the number of large earthquakes in Figure 4. Lunar declination is measured in degrees north and south of the celestial equator (Figure 13). The points north of the celestial equator have positive declinations, while those to the south have negative declinations. An object on the celestial equator has declination of $0^{\circ}$. The lunar declinations were taken from monthly tables published by Astropro and Lunar Living Astrology (Astropro (2007), and LLA). The $-28^{\circ}$ declination is when the moon is towards South Pole of the earth, while the $28^{\circ}$ declination is when the moon is towards north pole of the earth. At $0^{\circ}$ declination, the moon is in descending node while for $-0^{\circ}$ declination, the moon is in ascending node.

Figures 14 and 15 shows the positions of large earthquakes with respect to lunar declination during the years $2004-2008$ in the months of April to September and October to March. The closeness to 28, 0, -28 and $0^{\circ}$ can include \pm 2 days from these positions. In Figure 14, 28 out of 34 large earthquakes were close to these lunar positions. In Figure 15, 29 out of 39 large earthquakes are close to these lunar positions. In Figure 14 from April to September, more of large earthquakes occur near 28 and $0^{\circ}$ declinations, that is, towards descending node of lunar phase. In Figure 15 from October to March, the large earthquakes are less near $0^{\circ}$ while they are more near -28 and $-0^{\circ}$, that is, towards ascending node of lunar phase. The $0^{\circ}$ declination from April to September and $0^{\circ}$ declination from October to March are on the back side of the earth during its revolution around the sun. Therefore, it seems that rotation and revolution of the earth were responsible for these earthquakes. 
The above results show that the position of the Moon with respect to the axis of rotation of the earth plays an important role in triggering of earthquakes. The earth rotates at a speed of $1669 \mathrm{~km} / \mathrm{h}$ in west-east direction. The earth revolves around the sun at a speed of about $107000 \mathrm{~km} / \mathrm{h}$. The moon moves in a counterclockwise direction with an average orbital speed of about 3600 $\mathrm{km} / \mathrm{h}$. The sun-earth-moon system is very complex and it seems difficult to imagine that a stable equilibrium will exist all the time with these high speeds. The occurrence of large earthquakes near $28,0,-28$ and $-0^{\circ}$ declinations shows that interior of the earth is disturbed due to rotation of the earth when the moon crosses these positions. Probably the linear motion of the earth has some effect. The orientation of the lunar apse significantly affects the number and magnitude of earthquakes.

\section{CONCLUSION}

When the earth rotates on its own axis, with an inclination of $23.5^{\circ}$, the earth-moon interaction seems to affect the earth's angular momentum, which activates the molten lava to push the mantle. The minimum perigee near full moon in March of 1993 and 2002/2003 increased the number of earthquakes of magnitude 1.0 - 2.9. The minimum perigee near full moon in September of 1997 and 2006 reduced the number of earthquakes of magnitude 1.0 - 2.9. The minimum perigee near full moon in ascending node from 1995 to 1999 stabilized the number of earthquakes of magnitude 3.0 - 4.9. The minimum perigee near full moon in descending node from 1999 to 2004 increased the number of earthquakes of magnitude 3.0 - 4.9. The stable minimum perigee from 1994 to 1997 before full moon reduced the number of earthquakes of magnitude 5.0 - 5.9 and the stable minimum perigee from 2003 after the full moon increased the number of earthquakes of magnitude 5.0 - 5.9. The minimum perigee closer to full moon and nearer to south pole of the earth from 1994 to 1997 decreased the number of earthquakes of magnitude 5.0 to 5.9. The minimum perigee closer to full moon and nearer to north pole of the earth from 1997 to 2003 increased the number of earthquakes of magnitude 5.0 to 5.9. The minimum perigee before the full moon after 1994 decreased the number of earthquakes of magnitude 5.0 to 5.9 while the minimum perigee after the full moon after 2003, increased the number of these earthquakes. The orientation of the lunar apse parallel to the axis of rotation of the earth increases the number of large earthquakes. During the years 2004 to 2008, from April to September, more of large earthquakes were near 28 and $0^{\circ}$ declinations, that is, towards descending node of lunar phase. During 2004 to 2008, from October to March, the large earthquakes were more near -28 and $-0^{\circ}$, that is, towards ascending node of lunar phase. The $0^{\circ}$ declination from April to September and $-0^{\circ}$ declination from October to March are on the back side of the earth during its revolution around the sun. It seems that rotation and revolution of the earth are responsible for these earthquakes.

\section{REFERENCES}

Allen MW (1936). The lunar triggering effect on earthquakes in southern California, Bull. Seismol. Soc. Am., 25: 147-157.

Astropro (2007). Lunar declination cycle. http://www.astropro.com/homelE45.html

Bridge J (1999). Variability of mantle plumes-Controls and effects. Planetary Sci., 3-28th November.

Carrez P, Ferré D, Cordier P (2007). Implications for plastic flow in the deep mantle from modelling dislocations in $\mathrm{MgSiO}_{3}$ minerals. Nature. 446: (7131) 68-70.

Cotton LA (1922). Earth frequency, with special reference to tidal stresses in the lithosphere, Bull. Seismol. Soc. Am., 12: 47-198.

EMSC (2011). European-Mediterranean Seismological Centre http://www.emsc-csem.org/index.php?page=current\&sub=list

Emter D (1997). Tidal triggering of earthquakes and volcanic events, pp. 293-310 in Tidal Phenomena, Lect. Notes Earth Sci., vol 66, edited by H. Wilhelm, W. Zurn and H.G. Wenzel, Springer-Verlag, Berlin.

Geoscience Australia (2007). Phases of the Moon. http://www.ga.gov.au/geodesy/astro/moonphases/phase2007.jsp

Heaton TH (1982). Tidal triggering of earthquakes, Bull. Seismol. Soc. Am., 72: 2181-2200.

Helffrich GR, Wood BJ (2001). The Earth's mantle. Nature, 412: (6846) 501-507.

Hernlund JW, Tackley PJ (2007). Some dynamical consequences of partial melting in Earth's deep mantle. Phys. Earth Planet. Int., 162: $(1,2), 149-163$.

Jeffreys $H$ (1938). Aftershocks and periodicity in earthquakes, Gerlands Beitr. Geophys., 53: 111-139.

Knott CG (1886). Ethquake frequency, Trans. Japan Seismol. Soc., 9: $1-20$.

Lamkin VV (1966). Baikal earthquakes and luni-solar tides, Priroda, 9: 23-34.

Landsberg H (1940). Seasonal pressure changes and earthquake occurrence, Trans. Am. Geophys. Union, 227-228.

Leypoldt H (1941). Sea-level changes as trigger forces, Bull. Seismol. Soc. Am., 31: 233.

Loper DE (1998). Mantle plumes and their effect on the Earth's surface: a review and synthesis. Dyn. Atmos. Oceans, 27: (1-4) 35-54.

Lunar Living Astrology

http://www.lunarliving.org/calendars/declinations.php

(LLA).

Maruyama S, Santosh M, Zhao D (2007). Superplume, supercontinent, and post-perovskite: Mantle dynamics and anti-plate tectonics on the core-mantle boundary. Gondwana Res., 11: $(1,2) 7-37$.

Melchior PJ (1983). The tides of the planet Earth, $2^{\text {nd }}$ ed., 641 p.", Pergamon Press, Oxford.

Oeser E (1996). Historical Earthquake Theories, University of Vienna, http://www.univvie.ac.at/wissenschaftstheorie/heat/heat.htm

Perrine CD (1949). Periods in earthquake activity, Bull. Seismol. Soc. Am., 39: 109.

Putirka KD, Perfit M, Ryerson FJ, Matthew G, Jackson MG (2007). Ambient and excess mantle temperatures, olivine thermometry and active vs. passive upwelling. Chem. Geol., 241: (3-4) 177-206.

Rydelek PA, Sacks IS, Scarpa R (1992). On tidal triggering of earthquakes at Campi Flegrei, Italy, Geophys. J. Int., 109: 125-137.

Ricou LE (2004). Earth's tectonic history revisited in the light of episodic misfits between plate network and mantle convection. Tectnophys. 384: 285-300.

Samuel H, Bercovici D (2006). Oscillating and stagnating plumes in the Earth's lower mantle. Earth Planetary Sci. Lett., 248: 90-105.

Schellart WP, Freeman J, Stegman DR (2006). Subduction-induced mantle convection on Earth: Poloidal versus toroidal flow. Geochimica et_Cosmochimica Acta 70: (18), A561.

Sima BL, Agterberg FP (2006). A conceptual model for kimberlite emplacement by solitary interfacial mega-waves on the core mantle boundary, J. Geodyn., 41: 451-461.

Simmons NA, Forte AM, Grand SP (2006). Constraining mantle flow 
with seismic and geodynamic data: A joint approach. Earth Planetary Sci. Lett., 246(1-2): 109-124.

Stetson HT (1935). The correlation of deep-focus earthquakes with lunar hour angle and declination. Science, 82: 523.

Stevenson DJ (2003). Styles of mantle convection and their influence on planetary evolution, Comptes Rendus Geosci., 335(1): 99-111.

Sun W (1992). Seismic energy distribution in latitude and a possible tidal stress explanation, Phys. Earth Planet. Int., 71 (3-4): 205-206.

Trifunac MD (1970). On the statistics and possible triggering mechanism of earthquakes in southern California, Report EERL 7003, Earthquake Engineering Research Laboratory, Calif. Inst. Technol., pp. 1-56.

Tsuruoka H, Ohtake M, Sato H (1995). Statistical test of the tidal triggering of earthquakes: contribution of the ocean tide loading effect, Oceanogr. Literature Rev., 42: 1086.

USGS, NEIC (2011): Earthquake facts and statistics http://neic.usgs.gov/neis/qued/

Van Den Dungen FH, Cox JF, Micghem JV (1951). Sur la période annuelle de la fréquence de seismes", Acad. Roy. Belg. Classe Sci., 37: 1037.
Varga P, Grafarend E (1996). Distribution of the lunisolar tidal elastic stress tensor components within the Earth's mantle, Phys. Earth Planetary Int., 93 (3-4): 285-297.

Vidale JE, Agnew DC, Malcolm JS, Oppenheimer DH (1998). Absence of earthquake correlation with tides: An indication of high fault stress rate, J. Geophys. Res., 103: 24567-24572.

Walker J (1997). Lunar Perigee and Apogee calculator, http://www.fourmilab.ch/earthview/pacalc.html.

Walzer U, Hendel R (1999). A new convection fractionation model for the evolution of the principal geochemical reservoirs of the Earth's mantle, Phys. Earth Planetary Int., 112(3-4): 211-256.

Zhao D (2004). Global tomographic images of mantle plumes and subducting slabs: insight into deep Earth dynamics. Phys. Earth Planetary Int., 146(1-2): 3-34. 